LA-UR-01-4886

Approved for public release; distribution is unlimited.

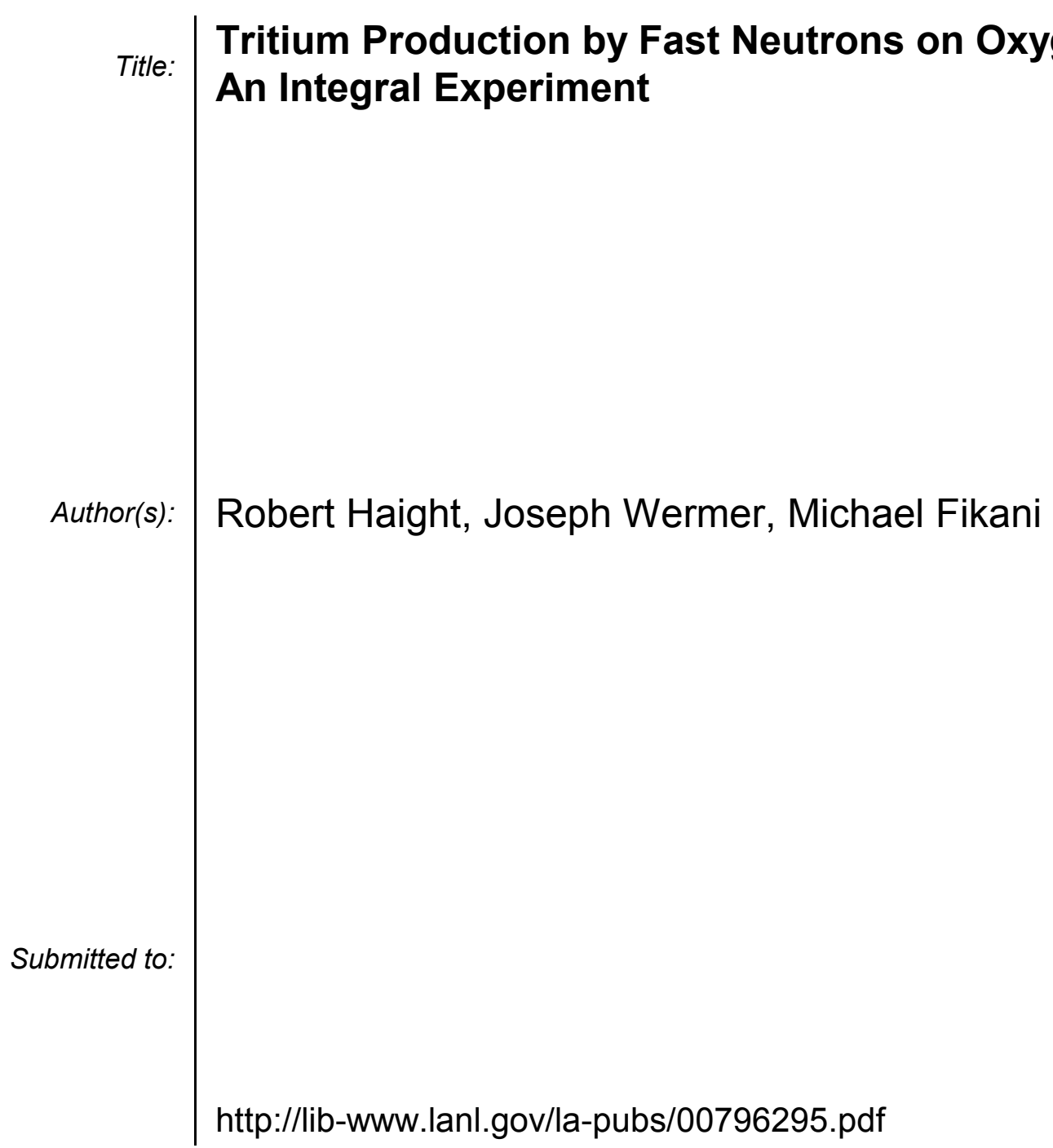

Los Alamos National Laboratory, an affirmative action/equal opportunity employer, is operated by the University of California for the U.S. Department of Energy under contract W-7405-ENG-36. By acceptance of this article, the publisher recognizes that the U.S. Government retains a nonexclusive, royaltyfree license to publish or reproduce the published form of this contribution, or to allow others to do so, for U.S. Government purposes. Los Alamos National Laboratory requests that the publisher identify this article as work performed under the auspices of the U.S. Department of Energy. Los Alamos National Laboratory strongly supports academic freedom and a researcher's right to publish; as an institution, however, the Laboratory does not endorse the viewpoint of a publication or guarantee its technical correctness. 


\title{
Tritium Production by Fast Neutrons on Oxygen: An Integral Experiment
}

\author{
Robert HAIGHT ${ }^{*}$, Joseph WERMER, Michael FIKANI \\ Los Alamos National Laboratory, Los Alamos, NM 87545, USA
}

\begin{abstract}
This report describes an integral experiment of tritium production in water by neutrons from the LANSCE/WNR spallation neutron source. Neutron energies covered the range from $1 \mathrm{MeV}$ to about 300 $\mathrm{MeV}$. The neutron fluence was determined with a ${ }^{238} \mathrm{U}$ fission chamber. After irradiation, the water samples were analyzed for tritium. The results are compared with calculations and agreement is found to within a factor of 2 .
\end{abstract}

KEYWORDS: tritium production, oxygen, neutron reactions, MCNPX

\section{Introduction}

Tritium can be produced by the interaction of fast neutrons with oxygen through reactions such as $(n, t),\left(n, n^{\prime} t\right)$, $(\mathrm{n}, \mathrm{pt})$, etc. (See Table 1). In acceleration-driven systems (ADS) such as for the accelerator-production of tritium (where the overall production of tritium is desired), and for accelerator-transmutation of waste and spallation neutron sources, fast neutrons can activate cooling water or other materials to produce unwanted tritium. Any neutrons that penetrate the massive shielding around the source could activate ground water by producing tritium and other radioisotopes. In considerations for designing such systems including the thickness of bulk shields, the possibility of tritium production must be considered. Because of the paucity of tritium-production data, we have undertaken an integral experiment to test neutron-induced tritiumproduction cross sections over a wide energy range, up to several hundred $\mathrm{MeV}$, characteristic of ADS. Our activation samples were water, which gives a test not only of this important material but also for all oxygen-containing compounds.

The lowest threshold for producing tritium in water is 15.39 MeV (Table 1). Tritium production data for neutrons on oxygen have been reported for neutron energies up to 38 $\mathrm{MeV}$. Qaim and Wölfle ${ }^{1)}$ reported results using a broad neutron-energy spectrum, centered at $22.5 \mathrm{MeV}$ with a width (FWHM) of $15.8 \mathrm{MeV}$. The lower-energy neutron range of this work extends below the threshold for all tritonproducing reactions on oxygen and therefore the interpretation of the results in terms of a cross section is not straightforward. The other tritium-production measurement by Shibata et $a l^{2)}$ used $\mathrm{p}+\mathrm{Be}$ and $\mathrm{p}+\mathrm{Li}$ neutron sources, which yield quasi-monoenergetic beams. Their results extend from 15 to $38 \mathrm{MeV}$. Other investigations have been based on techniques to detect tritons directly from thin foils bombarded with neutrons. Here again there could be some

\footnotetext{
* Corresponding author, Tel. +1-505-667-2829, Fax. +1-505 -6673705, E-mail: haight@lanl.gov.
}

difficulties because particle-detection techniques have thresholds, which make it difficult to detect all of the emitted tritons. Although these literature data are helpful indicators in suggesting cross sections for tritium production up to 40 $\mathrm{MeV}$, they are insufficient for application to spallation neutron sources where the energies extend to much higher energies.

Table 1 - Reactions of neutrons on oxygen that produce tritium and their thresholds

\begin{tabular}{lr}
\hline $16 \mathrm{O}(\mathrm{n}, \mathrm{xt})$ Reactions & $\begin{array}{c}\text { Threshold } \\
(\mathrm{MeV})\end{array}$ \\
\hline${ }^{14} \mathrm{~N}+\mathrm{t}$ & 15.39 \\
${ }^{13} \mathrm{C}+\mathrm{p}+\mathrm{t}$ & 23.42 \\
${ }^{13} \mathrm{~N}+\mathrm{n}+\mathrm{t}$ & 26.61 \\
${ }^{10} \mathrm{~B}+\alpha+\mathrm{t}$ & 27.74 \\
${ }^{12} \mathrm{C}+\mathrm{n}+\mathrm{p}+\mathrm{t}$ & 28.68 \\
${ }^{6} \mathrm{Li}+2 \alpha+\mathrm{t}$ & 32.48 \\
${ }^{3 \alpha}+\mathrm{d}+\mathrm{t}$ & 34.05 \\
${ }^{8} \mathrm{Be}+\mathrm{d}+\mathrm{t}$ & 34.14 \\
${ }^{9} \mathrm{Be}+\mathrm{p}+\alpha+\mathrm{t}$ & 34.74 \\
$\mathrm{n}+\mathrm{p}+3 \alpha+\mathrm{t}$ & 36.41 \\
${ }^{9} \mathrm{~B}+\mathrm{n}+\alpha+\mathrm{t}$ & 36.71 \\
${ }^{5} \mathrm{He}+\mathrm{p}+2 \alpha+\mathrm{t}$ & 37.36 \\
${ }^{5} \mathrm{Li}+\mathrm{n}+2 \alpha+\mathrm{t}$ & 38.50 \\
${ }^{11} \mathrm{C}+2 \mathrm{t}$ & 39.56 \\
13 reactions & 40 to 50 \\
${ }^{38}$ reactions & 50 to 60
\end{tabular}

Related experimental results include those made at LANSCE of the ${ }^{16} \mathrm{O}(\mathrm{n}, \mathrm{x} \gamma){ }^{14} \mathrm{~N}^{*}(2.313 \mathrm{MeV})$ reaction which can take place by $(n, t),(n, n d)$, and $(n, p+2 n)$ channels. ${ }^{3)}$ This approach gives excellent data for modeling the reactions but gives data of a different sort than the direct tritium production experiments because (1) it does not measure the contribution for reactions that bypass this excited state, and (2) it does not differentiate between reactions $(n, t),(n, n+d)$ and $(n, n+n+p)$. 
The present experiment is an integral experiment of neutron-induced tritium production in water integrated over a particular neutron spectrum that extends up to several hundred $\mathrm{MeV}$. Simply put, water samples were irradiated in a neutron spectrum and subsequently analyzed for accumulated tritium. To estimate the contributions of the various neutron energies, we show the neutron source spectrum, ${ }^{4)}$ an evaluated tritium production cross section, ${ }^{5)}$ and the product of these two functions in Fig. 1. This figure indicates that most of the tritium in this experiment is expected to be produced for neutron energies in the range of about 20 to $150 \mathrm{MeV}$.

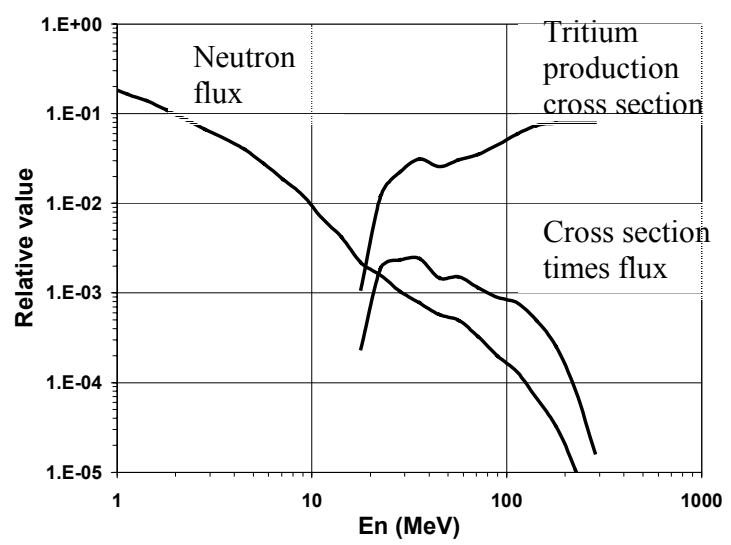

Fig. 1 Relative shapes versus neutron energy of the calculated neutron flux, ${ }^{4)}$ the evaluated tritium production cross section, ${ }^{5)}$ and the product of the two to show at which neutron energies the tritium production is expected to take place.

In this report, we describe the experiment, give results, and compare the results with model calculations using presently available evaluated data.

\section{Experiment}

Three water samples were irradiated over a period of 5 days at the 90-degree-left beam line at the Weapons Neutron Research (WNR) facility at the Los Alamos Neutron Science Center (LANSCE), which has been described previously. ${ }^{6,7)}$ The physical layout of the irradiation is shown schematically in Fig. 2. The WNR source was operated in its usual mode with typical currents of 3 microamperes on the neutron production target. The micropulse spacing, used to monitor the neutron flux spectrum, was 1.8 microseconds, and the macropulse rate was $100 \mathrm{~Hz}$.

Collimation of the neutron beam was the same as used in other experiments ${ }^{8}$ and shaped the beam to a square $5 \mathrm{~cm} \times 5$ $\mathrm{cm}$ with $1 \mathrm{~cm}$ triangles cut off the corners. A clean-up collimator was placed just in front of the water samples to intercept neutrons scattered from the defining collimator. Three water samples were placed 9.13 meters from the source. The water was obtained from the local supermarket and, under assay, showed low initial values of tritium.
Surprisingly, this water had a slightly lower tritium content than that obtained from "deep wells" in the Los Alamos area.

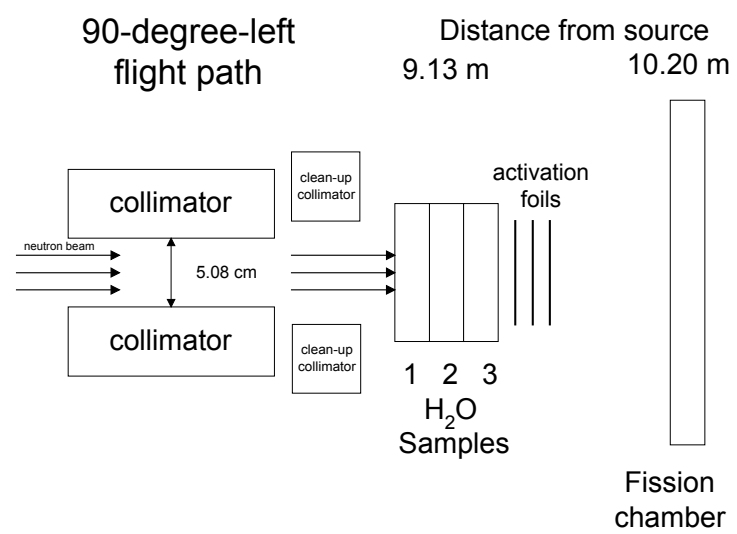

Fig. 2 Schematic setup for the irradiation showing the collimator (square except for $1 \mathrm{~cm}$. triangles in each corner), the cleanup collimator, water samples, activation foils and the fission chamber.

The water was held in cells specially constructed for this experiment of acrylic $\left(\mathrm{C}_{5} \mathrm{H}_{8} \mathrm{O}_{2}\right)$ with entrance and exit windows $0.76 \mathrm{~mm}$ thick epoxied to a cylindrical ring 76.2 $\mathrm{cm}$ in inner diameter. This size was chosen so that the neutron beam did not intersect the ring but rather passed only through the $0.76 \mathrm{~mm}$ acrylic entrance window, the water, and the $0.76 \mathrm{~mm}$ exit window. These rings had a wall thickness of $6.4 \mathrm{~mm}$ and were $14.0 \mathrm{~mm}$ long, the last dimension being the nominal path length traversed by the neutron beam through the water. At the top of the cells, a threaded hole permitted filling and then resealing with a plastic screw. The mass of water in each cell was determined by weighing the cells before and after filling and, as a check after the irradiation, before and after the water was removed. The actual path length of the (unscattered) neutrons was determined by measuring the outside dimensions of the cells to test that, when filled, the cell walls did not deform. In fact, very little deformation was observed. The masses of the individual water samples are given in Table 2.

Just downstream of the water samples, we placed three activation foils, $\mathrm{Cu}, \mathrm{Al}$, and $\mathrm{Nb}$, with all foils being larger than the neutron beam. Backing foils of 25 micron polyethylene after each activation foil served to catch any nuclei recoiling. In fact, when these backing foils were counted separately after the irradiation, their activity was negligible compared with that in the activation foils themselves. Results from these activation foils will be presented in a separate report.

At a distance of 10.20 meters from the source, that is 1.07 meters beyond the water samples, a ${ }^{238} \mathrm{U}$ fission chamber $\left.{ }^{9}\right)$ monitored the neutron flux and flux spectrum by time of flight. The reference ${ }^{238} \mathrm{U}$ fission cross section used to deduce the neutron fluence and fluence spectrum was taken from the work of Lisowski et al. ${ }^{10)}$

Following the irradiation, the water samples were analyzed for tritium both at Los Alamos and commercially. The commercial measurement was carried out by Paragon 
Table 2 Results of tritium analyses

\begin{tabular}{|c|c|c|c|c|c|c|c|c|}
\hline \multirow[t]{3}{*}{ Cell no. } & Mass & Paragon & Paragon & Net & Net & Net atoms & & Tritons \\
\hline & $\mathrm{H} 2 \mathrm{O}$ & results & uncertainty & & uncertainty* & per $\mathrm{ml}$ & uncertainty & produced \\
\hline & (g) & $\mathrm{pCi} / \mathrm{ml}$ & $\mathrm{pCi} / \mathrm{ml}$ & $\mathrm{pCi} / \mathrm{ml}$ & $\mathrm{pCi} / \mathrm{ml}$ & $\mathrm{t} / \mathrm{ml}$ & $\mathrm{t} / \mathrm{ml}$ & \\
\hline 1 & 61.2 & 9.7 & 2.5 & 7.75 & 3.0 & $1.60 \mathrm{E}+08$ & $6.20 \mathrm{E}+07$ & $9.79 \mathrm{E}+09$ \\
\hline 2 & 58.1 & 10.4 & 2.6 & 8.45 & 3.0 & $1.74 \mathrm{E}+08$ & $6.20 \mathrm{E}+07$ & $1.01 \mathrm{E}+10$ \\
\hline 3 & 62.7 & 11.2 & 2.6 & 8.25 & 3.0 & $1.70 \mathrm{E}+08$ & $6.20 \mathrm{E}+07$ & $1.07 \mathrm{E}+10$ \\
\hline \multicolumn{2}{|c|}{ Blank(avg) } & 1.95 & 2.1 & - & & & & \\
\hline & & & & & & & & $+/-35 \%$ \\
\hline \multicolumn{7}{|c|}{${ }^{*}$ uncertainty estimated from measurements and correlated uncertainties } & & \\
\hline
\end{tabular}

Analytics, Inc. of Fort Collins, Colorado. The results from these two approaches are in essential agreement.

\section{Results}

The neutron fluence spectrum as measured by the fission chamber is given in Fig. 3. This spectrum can be corrected for transmission through the water samples and the activation foils to give the neutron spectrum incident on the first water cell. For this correction, we use neutron total cross sections for these intervening materials. ${ }^{11,12}$ The deduced incident spectrum is shown in Fig. 3. The measured spectrum is very similar in shape to the expected spectrum (Fig. 1). In Fig. 4 the cumulative integral of tritium production shows that about half of the tritium in this experiment is produced for neutron energies below $70 \mathrm{MeV}$.

Results from the tritium analyses are given in Table 2.

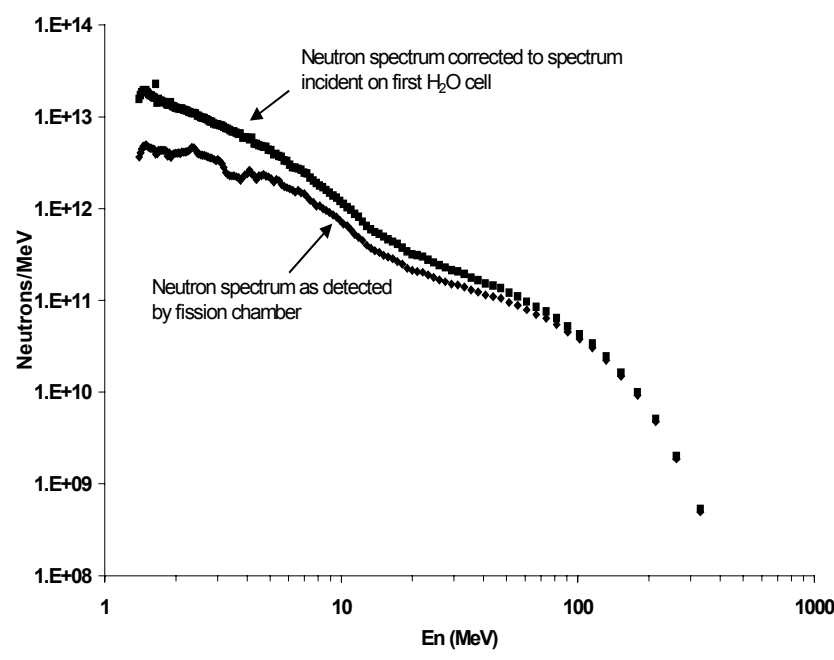

Fig. 3 Observed neutron spectrum at the fission chamber (lower points). Correcting for absorption and scattering in the cells and the foils, we obtain the spectrum incident on the first cell (upper curve).

\section{Discussion and comparison with calculations}

To compare the tritium concentrations measured with what would be expected, Monte Carlo calculations of the neutron transport are necessary because of the possibility of multiple interactions in the cells. Ideally, one would like a very thin cell to make such calculations unnecessary. However, the cells needed to be thick enough to stop most of the recoiling tritons before they could escape. Furthermore, the three cells were placed in order to test for buildup of the tritium concentration as a function of depth in the water. The MCNPX Monte Carlo transport code ${ }^{13)}$ was used for the calculations.

We can make a simple calculation by assuming that the cells are thin to neutrons and that there are no losses due to energetic tritons escaping the cells and no additional tritons due to energetic tritons entering the water in the cells. In this case, we integrate the cross section of Chadwick ${ }^{5)}$ over the actual neutron energy spectrum and find that the number of tritons expected is $2.0 * 10^{10}$. This is to be compared with the measured production of $1.0 * 10^{10}$ tritons, with an uncertainty in the tritium measurement of about $35 \%$.

The uncertainties in the present measurement are dominated by uncertainties in the tritium analysis (30-35\%). Other uncertainties include those of the ${ }^{238} \mathrm{U}$ fission cross section (which become significant, maybe 20\% above 100 $\mathrm{MeV})$, the amount of ${ }^{238} \mathrm{U}$ in the fission chamber $(10 \%$ due to possible non-uniformities), the electronic dead time $(5 \%)$, and the geometry of the water cells (estimated to be about $5 \%$ ).

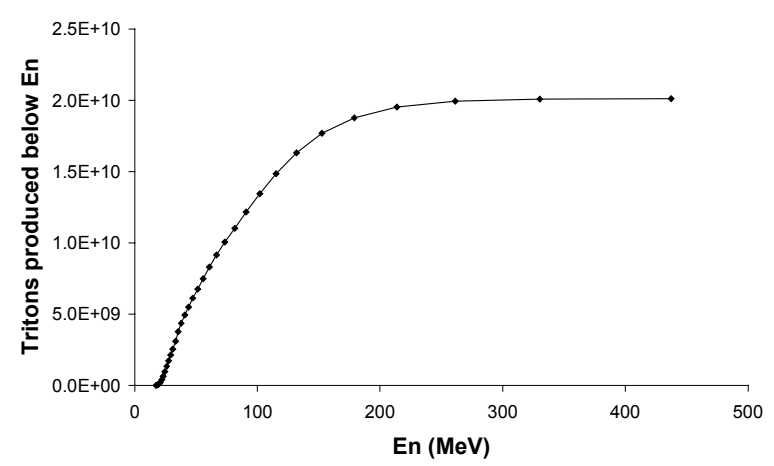

Fig. 4 Cumulative tritium production as a function of neutron energy. Tritium produced below a neutron energy En is plotted versus En.

\section{Conclusions}

This experiment tests the tritium production cross section over the neutron energy range from threshold to over 200 $\mathrm{MeV}$ in an integral sense. We have shown that readily detectable amounts of tritium can be produced at LANSCE/WNR in a few days. The results show reasonable 
agreement with calculations to about a factor of 2 with an uncertainty in the measurement of about $35 \%$.

Further investigations of this sort are very attractive. Because of the neutron source strength at LANSCE/WNR has been doubled since this irradiation was done, a better signal-to-background for tritium analysis could be obtained in the same running time. Therefore, a duplicate experiment to this one would provide data with smaller uncertainties. Further experiments could test the tritium production cross sections at higher average neutron energies by using moreforward flight paths at LANSCE/WNR and by reducing the flux of neutrons below $70 \mathrm{MeV}$ by $\mathrm{CH}_{2}$ absorbers in the beam.

\section{Acknowledgments}

We are grateful to S. A. Wender, B. Takala and the WNR and LANSCE operations teams for providing excellent beam for this experiment. The cells were constructed by W. Pierce, who added many significant design ideas. This work has benefited from the use of the Los Alamos Neutron Science Center at the Los Alamos National Laboratory. This facility is funded by the US Department of Energy and operated by the University of California under Contract W7405-ENG-36. This work was encouraged and supported by L. Waters of the APT program.

\section{References}

1) S. M Qaim and R. Wölfle, "Triton Emission in the Interaction of Fast Neutrons with Nuclei," Nucl. Phys., A295 (1978) 150.

2) S. Shibata, T. Shibata, M. Imamura, T. Ohkubo, S. Satoh, Y. Uwamino, N. Morikawa and N. Nogawa, "Measurements of the Production Cross Sections of Tritium from Oxygen Using p-Be and p-Li Neutrons up to En = $38 \mathrm{MeV}$," Radiochimica Acta, 75, 1-6 (1996).

3) R. O. Nelson and A. Michaudon, "High-Resolution Cross Section Measurements of Photon Production from ${ }^{16} \mathrm{O}(\mathrm{n}, \mathrm{x} \gamma)$ Reactions for Neutron Energies between 4 and 200 MeV," LA-UR-99-4170, Los Alamos National Laboratory (1999).

4) Gary Russell - private communication (1990).

5) M. B. Chadwick, P. G. Young, S. Chiba, et al., " Cross Section Evaluations to $150 \mathrm{MeV}$ for Accelerator-Driven Systems and Implementation in MCNPX," ," Nucl. Sci. Eng., 131, 293 (1999) and private communication (2000).
6) P. W. Lisowski, C. D. Bowman, G. J. Russell, and S. A. Wender, "The Los Alamos National Laboratory Spallation Neutron Sources," Nucl. Science and Eng., 106, 208 (1990).

7) H. Condé, R. Haight, H. Klein and P. Lisowski, "New Neutron Facilities for Nuclear Data Measurements at En $>10 \mathrm{MeV}, "$ Proc. Int. Conf. on Nuclear Data for Science and Technology, Jülich 13-17 May, 1991, ed. S. M. Qaim, (Springer-Verlag, Berlin 1992) p. 386.

8) R. C. Haight, F. B. Bateman, S. M. Sterbenz, S. M. Grimes, O. A. Wasson, P. Maier-Komor and H. Vonach, "An Update on (n,charged particle) Research at WNR," Fusion Engineering and Design, 37, 73-77 (1977).

9) S. A. Wender, S. Balestrini, A. Brown, R. C. Haight, C. M. Laymon, T. M. Lee, P. W. Lisowski, W. McCorkle, R. O. Nelson, W. Parker, and N. W. Hill, "A Fission Ionization Detector for Neutron Flux Measurements at a Spallation Source," Nucl. Instr. Methods in Physics Research A336, 226 (1993). Phys. Rev,. C47, 237-247 (1993).

10) P. W. Lisowski, A. Gavron, W. E. Parker, J. L. Ullmann, S. J. Balestrini, A. D. Carlson, O. A. Wasson and N. W. Hill, "Fission Cross Sections in the Intermediate Energy Region," Proc. Specialists, Meeting opn Neutron Cross Sections Standards for the Energy Region above $20 \mathrm{MeV}$, Nuclear Energy Agency report NEANDC-305'U', Uppsala, Sweden 21-23 May, 1991, pp. 177-186

11) R. W. Finlay, W. P. Abfalterer, G. Fink, E. Montei, T. Adami, P. W. Lisowski, G. L. Morgan, and R. C. Haight, "Neutron Total Cross Sections at Intermediate Energies," Phys. Rev,. C47, 237-247 (1993).

12) ENDF/B-VI Evaluated Nuclear Data File, available from the National Nuclear Data Center, Brookhaven National Laboratory.

13) MCNPX Users Manual, ed. Laurie S. Waters, Accelerator Production of Tritium report (1999). 